\title{
Using scale heights derived from bottomside ionograms for modelling the IRI topside profile
}

\author{
B. W. Reinisch ${ }^{1}$, X. Huang ${ }^{1}$, A. Belehaki ${ }^{2}$, and R. Ilma ${ }^{3}$ \\ ${ }^{1}$ Environmental, Earth and Atmospheric Sciences Department, Center for Atmospheric Research, University of \\ Massachusetts Lowell, USA. \\ ${ }^{2}$ Institute for Space Applications and Remote Sensing, National Observatory of Athens, Greece \\ ${ }^{3}$ Jicamarca Radio Observatory, Lima, Peru
}

\begin{abstract}
Groundbased ionograms measure the Chapman scale height $H_{T}$ at the F2-layer peak that is used to construct the topside profile. After a brief review of the topside model extrapolation technique, comparisons are presented between the modeled profiles with incoherent scatter radar and satellite measurements for the mid latitude and equatorial ionosphere. The total electron content TEC, derived from measurements on satellite beacon signals, is compared with the height-integrated profiles ITEC from the ionograms. Good agreement is found with the ISR profiles and with results using the low altitude TOPEX satellite. The TEC values derived from GPS signal analysis are systematically larger than ITEC. It is suggested to use $H_{T}$, routinely measured by a large number of Digisondes around the globe, for the construction of the IRI topside electron density profile.
\end{abstract}

\section{Introduction}

In a number of recent publications we have shown that the topside electron density profiles can be derived with good accuracy from the ionograms of groundbased ionosondes (Reinisch and Huang, 2001; Belehaki et al., 2003). An $\alpha$ Chapman function with constant scale height $H_{T}$ is assumed for the topside electron density distribution,

$C(h)=N m F 2 \cdot \exp \left[\frac{1}{2}\left(1-z-e^{-z}\right)\right] ;$

$z=\frac{h-h m F 2}{H_{T}}$.

The scale height $H_{T}$ is derived from the measured bottomside profile, which can be represented in terms of $\alpha$ Chapman functions with a scale heights $H(h)$ that vary with height (Rishbeth and Garriott, 1969):

Correspondence to: B. W. Reinisch

(bodo_reinisch@uml.edu)

$$
\begin{aligned}
& N(h)=N_{m}\left(\frac{H_{m}}{H(h)}\right)^{\frac{1}{2}} \exp \left\{\frac{1}{2}[1-y-\exp (-y)]\right\} ; \\
& y=\int_{h_{m}}^{h} \frac{d h}{H(h)} .
\end{aligned}
$$

The subscript $m$ refers to the values at the layer peak. The value $H_{m}$ at the F2-layer peak can be calculated from the known function $N(h)$ (Huang and Reinisch, 2001). Figure 1 illustrates the process of constructing the topsisde profile. The bottomside profile on the left is derived from a daytime ionogram recorded in Kokobunji, Japan, on 8 March 1999. The center panel shows the height variation of the calculated scale height $H(h)$ with a maximum in the F1-region and minimal variation near the $\mathrm{F} 2$ peak. It seems therefore reasonable to assume that $H(h>h m F 2) \approx H(h m F 2)$ for a few hundred $\mathrm{km}$ above $h m F 2$. The topside profile is then calculated with $H_{T}=H(h m F 2)$ (right panel).

\section{Validation of topside extrapolation technique}

The best validation of the topside extrapolation technique is obtained at locations where an incoherent scatter radar (ISR) and an ionosonde measure vertical profiles simultaneously. Figures 2 and 3 show comparisons of such measurements at a mid latitude site (Millstone Hill, Massachusetts, $42^{\circ} \mathrm{N}$ ) and the magnetic equator (Jicamarca, Peru). The Millstone Hill data in Fig. 2, showing the integrated electron content up to $800 \mathrm{~km}$ for four seasons in 1990 for all days for which ISR profile measurements were made, demonstrate the very good agreement between the two techniques. In Fig. 3, time averaged ISR profiles (red) at Jicamarca are compared with the hourly Digisonde profiles (green) for the available ISR observations from 19:00 LT on 11 June to 04:00 LT on 12 June 2002. While there is mostly very good agreement up to $800 \mathrm{~km}$ altitude in the evening and early night hours, noticeable differences occur above $600 \mathrm{~km}$ at 03:00 and 04:00 LT 

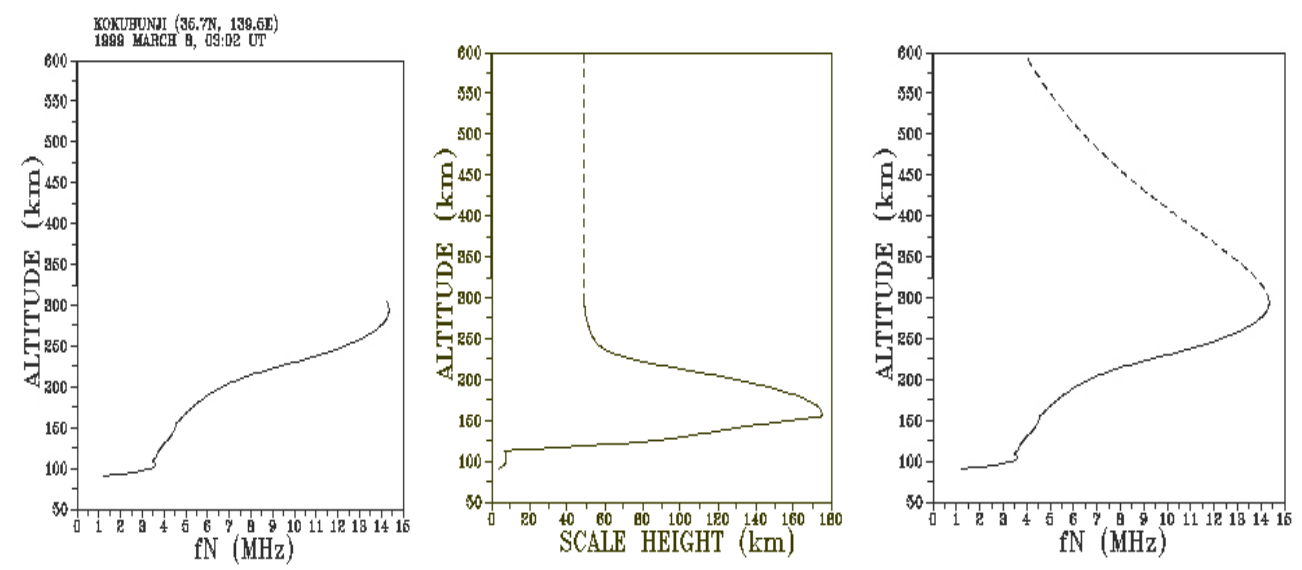

Fig. 1. Construction of the topside profile (right, dotted curve) from the measured bottomside profile (left) using the derived Chapman scale height (center).
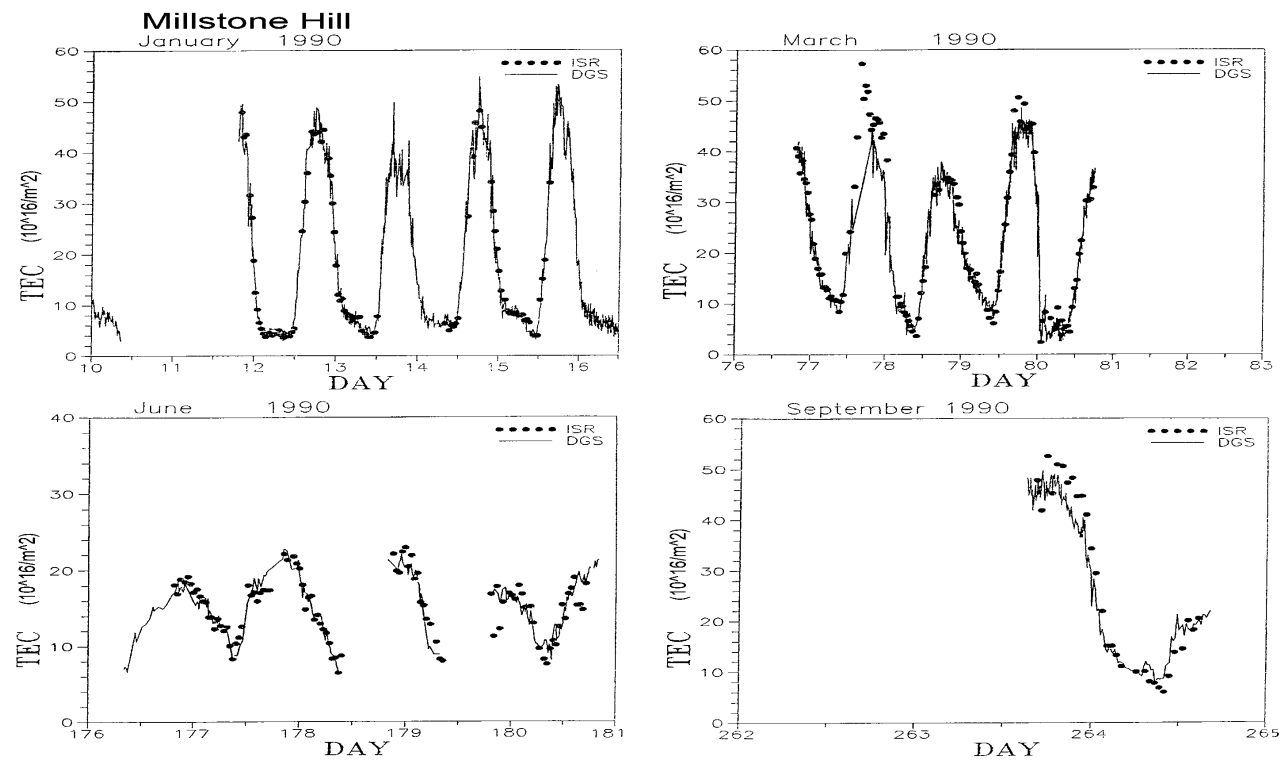

Fig. 2. Diurnal variations of the height-integrated electron density profiles at Millstone Hill derived from ISR (dotted) and Digisonde (thin line) measurements for January, March, June, and September 1990.

(08:00 and 09:00 UT). When more ISR profiles become available, we will find out whether the ionosonde technique systematically underestimates $H_{T}$ at late night hours, and how it performs during the daytime in the equatorial ionosphere.

The height-integrated ionosonde profiles represent the ionospheric total electron content "ITEC", and comparisons with TEC measurements on satellite beacon signals can be made. Best agreement should be expected from vertical TOPEX observations when the satellite orbit passes over the ionosonde site. Jicamarca is close to the Pacific Ocean, which is important since TOPEX TEC measurements are only possible over ocean surfaces, and suitable TOPEX passes (A. Komjathy, personal communication) were selected for comparison.
For March and April 1998 TOPEX had 9 passes close to Jicamarca. Figure 4 shows the TOPEX TEC values (red) during the $10 \mathrm{~s}$ of closest approach to Jicamarca, superimposed on the diurnal Digisonde ITEC variations. The lengths of the TOPEX bars indicate the TEC variation observed during $10 \mathrm{~s}$. Until 21 March the TOPEX passes occurred at nighttime $(\mathrm{LT}=\mathrm{UT}-5 \mathrm{~h})$ confirming the agreement between the techniques that was shown in Fig. 3. The measurements on daytime passes on and after 28 March show also good agreement during daytime.

Vertical TEC data derived from oblique GPS signals (Sardon et al., 1994; Jakowski, 1996) contain the plasmaspheric electron content (Lund et al., 1999), since GPS satellites orbit at $\sim 20000 \mathrm{~km}$ altitude. Comparing GPSTEC with ITEC should therefore show a systematic difference. Figures 5 and 6 show GPSTEC and ITEC data for Athens, Greece $\left(38^{\circ} \mathrm{N}\right)$. 
Hourly average of electron density profile over Jicamarca - ISR VS DPS
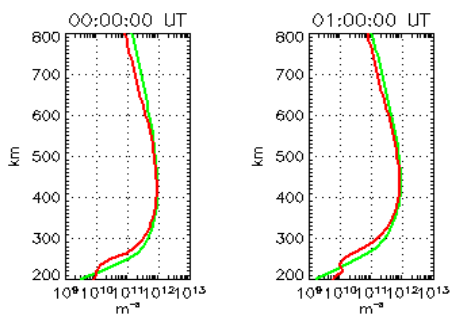
Day: 12-Jun-2002
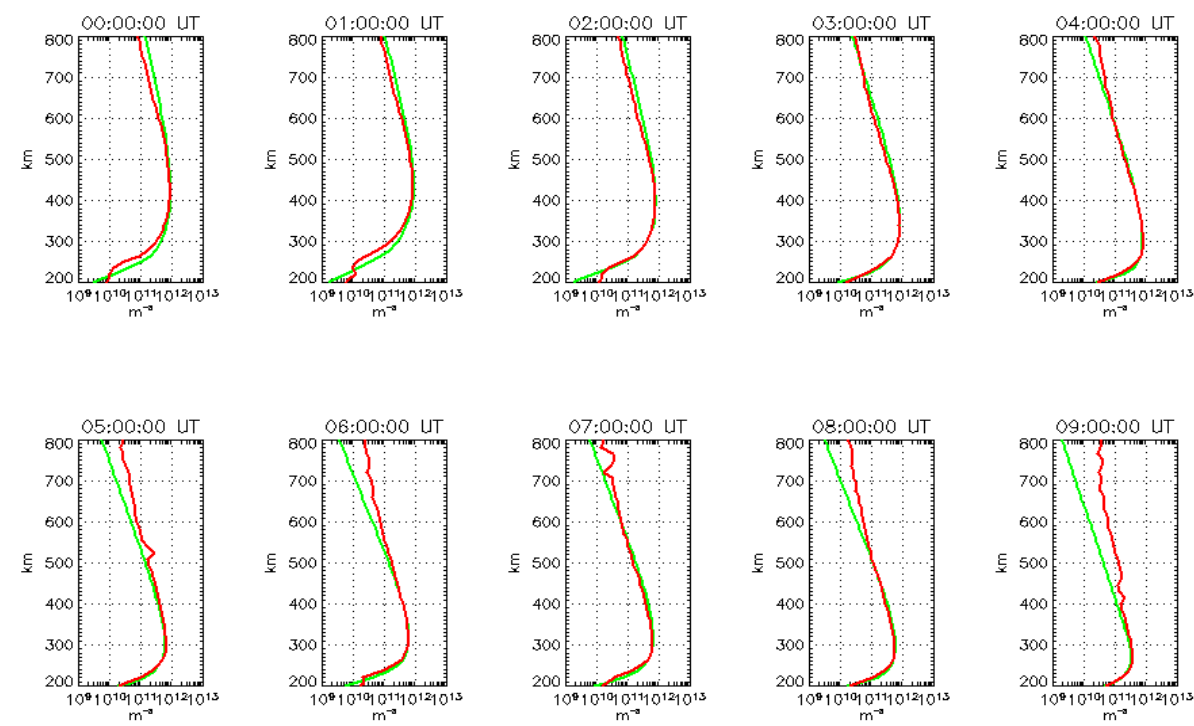

Fig. 3. Hourly nighttime F-layer profiles from ISR (red) and Digisonde (green) measurements at Jicamarca.

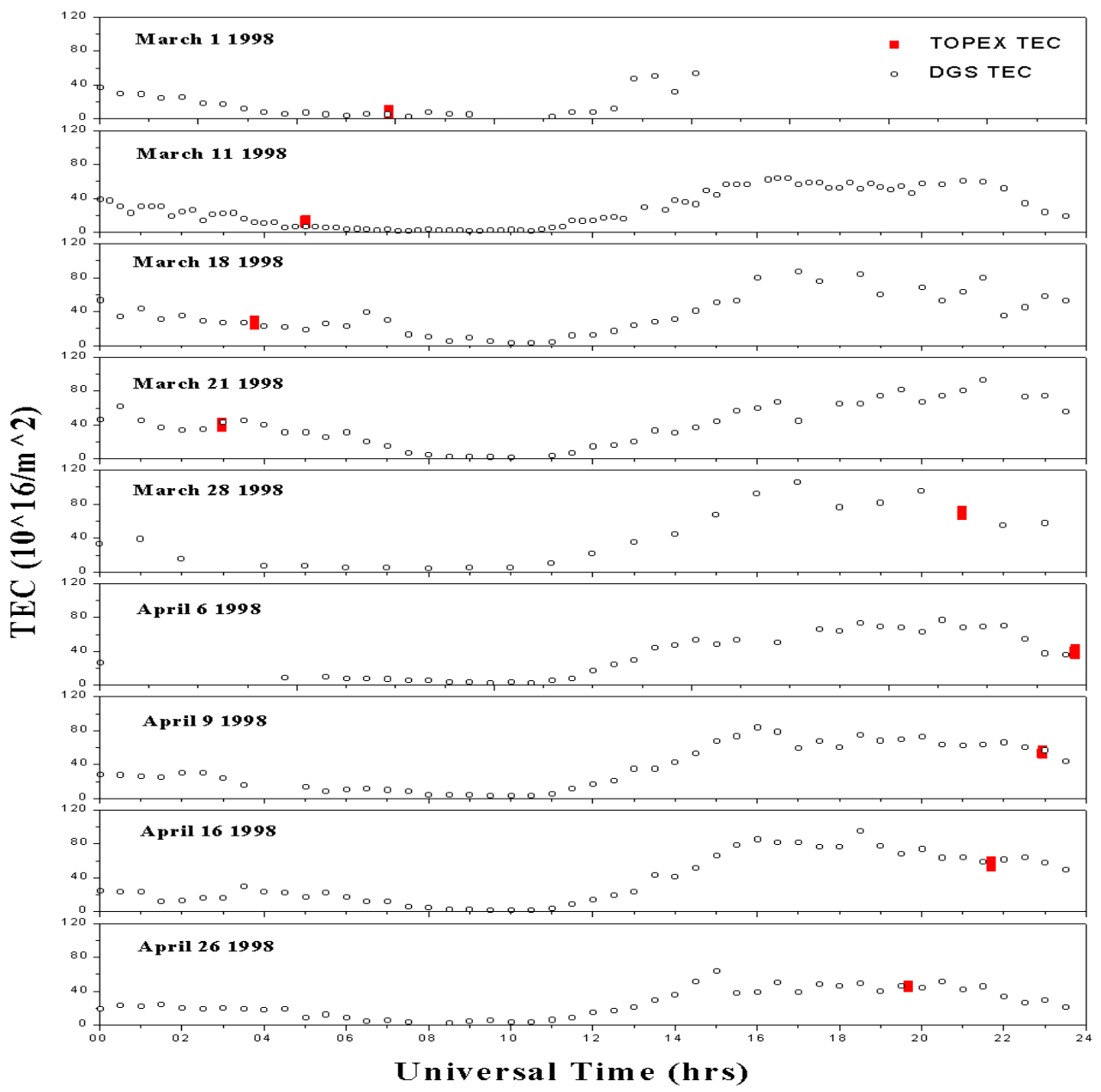

Fig. 4. Diurnal variation of Digisonde ITEC at Jicamarca compared with TOPEX TEC (red) results. 
March 2001
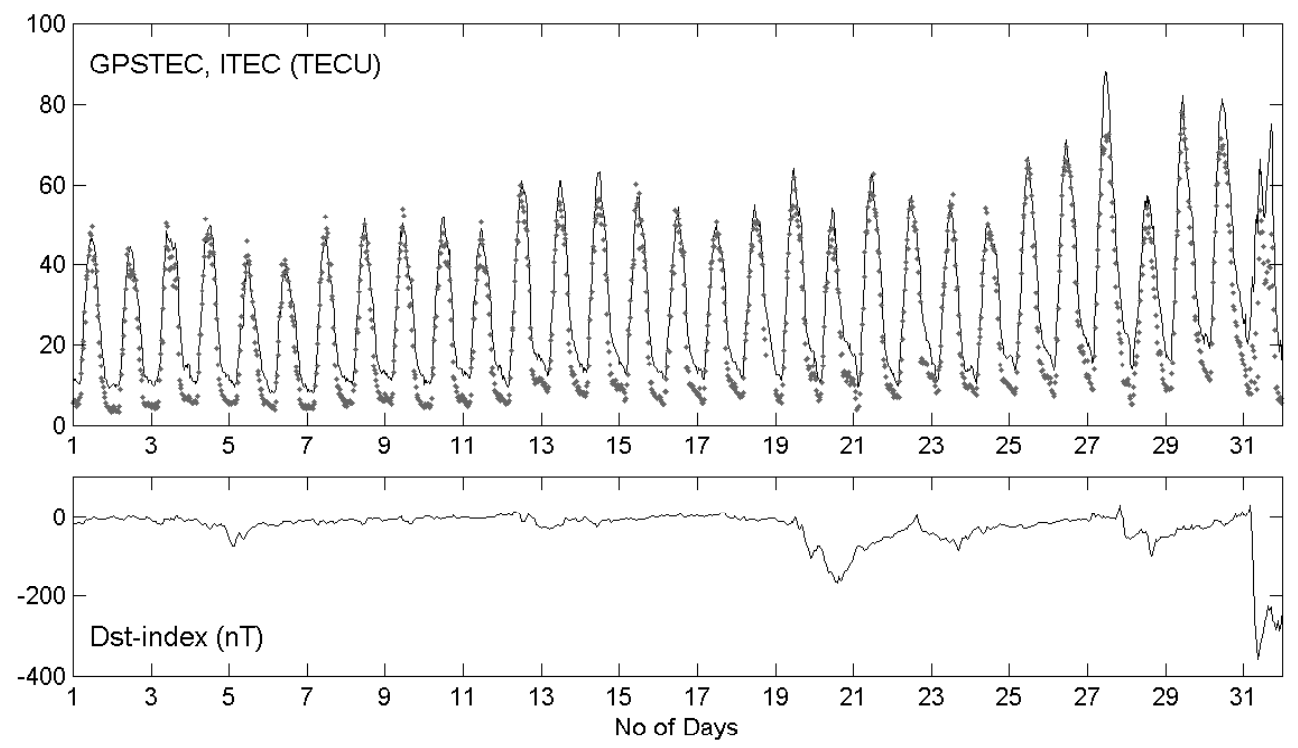

Fig. 5. Diurnal variation of GPSTEC (solid line) and ITEC (dotted line) at Athens, Greece, and the Dst-index (lower panel) during March 2001.
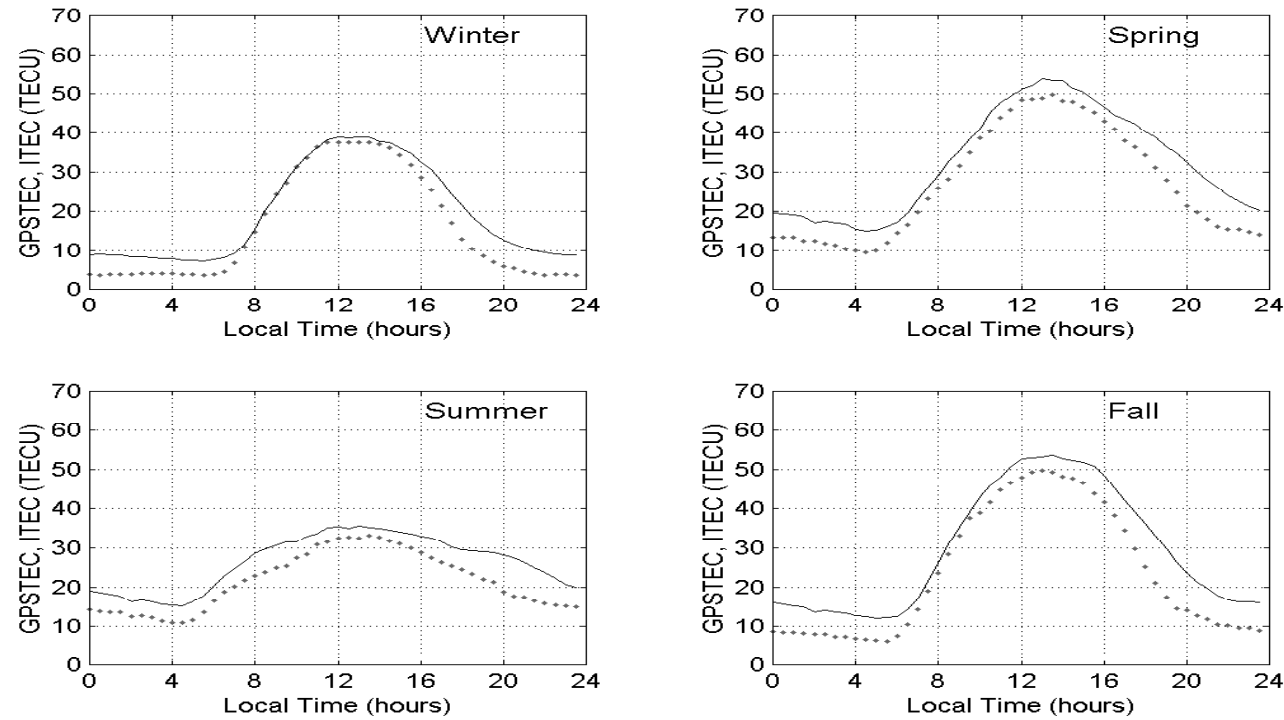

Fig. 6. Diurnal variation of GPSTEC (solid lines) and ITEC (dotted lines) for the four seasons, using the mean of the monthly median values for Athens, Greece, 2000/2001.

The diurnal variations in March 2001 again confirm the good correlation between the techniques, even during geomagnetic storms (Belehaki et al., 2004). The mean of the monthly median values for the four seasons (Fig. 6) clearly reveals the systematic difference between GPSTEC and ITEC, interpreted by Belehaki et al. (2004) as the diurnal and seasonal variations of the plasmaspheric contribution to GPSTEC.

\section{Discussion}

Evidence has been presented that the topside profiles at mid and low latitudes can be derived from the bottomside profiles measured by groundbased ionosondes. Only three characteristics are required, $N m F 2, h m F 2$, and $H_{T}$, all of them automatically determined with modern ionosondes. We therefore suggest that the scale heights $H_{T}$, routinely determined in the global Digisonde network and from other suitable ionosondes, be statistically analyzed and used as an input for the construction of the IRI topside electron density model. 
Acknowledgement. The UML authors were supported by the AF Research Laboratory under Contract Number F19628-02-C-0092.

\section{References}

Belehaki, A., Jakowski, N., and Reinisch, B. W.: Comparison of ionospheric ionization measurements over Athens using ground ionosonde and GPS derived TEC values, Radio Sci., 38, 6, 1105 , 2003.

Huang, X. and Reinisch, B. W.: Vertical total electron content from ionograms in real time, Radio Science, 36, 36, 2, 335-342, 2001.

Jakowski, N.: TEC Monitoring by Using Satellite Positioning Systems, Modern Ionospheric Science, (Eds. H. Kohl, R. Rüster, K. Schlegel), EGS, Katlenburg-Lindau, ProduServ GmbH Verlagsservice, Berlin, 371-390, 1996.
Lunt, N., Kersley, L., and Baily, G. J.: The influence of the protonosphere on GPS observations: Model simulations, Radio Sci., 34, 2, 725-732, 1999.

Reinisch, B. W. and Huang, X.: Deducing topside profiles and total electron content from bottomside ionograms, Adv. Space Res., 27, 1, 23-30, 2001.

Rishbeth, H. and O.K Garriott, Introduction to ionospheric physics, Academic Press, New York, 1969.

Sardon, E., Rius, A., and Zarraoa, N.: Estimation of the transmitter and receiver differential biases on the ionospheric total electron content from Global Positioning System observations, Radio Sci., 29, 577-586, 1994. 